Note

\title{
An application of the airport service quality model in South Africa
}

\author{
Berendien Lubbe*, Anneli Douglas, Julia Zambellis \\ Department of Tourism Management, University of Pretoria, Duxbury Road, Hatfield, Pretoria, Gauteng 0002, South Africa
}

Keywords:

Airports

Business travellers

Leisure travellers

Service quality

Expectations

Performance

South Africa

\begin{abstract}
A B S T R A C T
Passengers' expectations of service quality at airports are becoming increasingly important as air traffic grows. This research investigated passengers' perceptions of airport service quality at O.R. Tambo International Airport, South Africa. An existing model placing the concept of passenger expectations central to measuring an airport's specific level of performance was applied. The results proved significant in terms of the investment made by the airport in staff training and highlighted areas for improvement. The results show that business travellers and leisure travellers have different opinions regarding the importance of services offered by airports and of the level of performance at ORTIA in particular. Significant differences also occur in the perceptions of frequent travellers and infrequent travellers.
\end{abstract}

() 2010 Elsevier Ltd. All rights reserved.

\section{Background}

Since 2006, the Airports Company of South Africa (ACSA) has invested about $\$ 2.5$ billion expanding and upgrading infrastructure across its network of airports, aimed at matching infrastructure to anticipated tourist traffic growth. What differentiates these investments from others is the 2010 FIFA World Cup because all infrastructure investments essential to success was brought forward. Under this investment programme focus was placed on the end-user or air traveller with an airport-wide staff training programme being instituted aimed at providing exceptional levels of service, particularly for the period of the tournament (Airports Company South Africa, 2010). As a result, much media attention was focused on the quality of service to be expected at South African airports and particularly at O.R. Tambo International Airport (ORTIA) in Johannesburg, the key entry point into the country. Here we undertake an evaluation of whether ACSA was achieving its goal in meeting expectations on service quality at ORTIA. The concept of expectations underlies the selection of Fodness and Murray's (2007) methodology for measuring service quality with its focus on passenger expectations in service quality. Fodness and Murray suggest that for a model to be fully developed as a global measure of airport service quality, application within different cultural contexts is necessary. Thus, a secondary aim here is to apply the model of Fodness and Murray in a specific cultural context.

Previous work on airport service quality has primarily focussed on service performance measure methodologies and Fodness and

\footnotetext{
* Corresponding author. Tel.: +27 124204 102; fax: +27 124203349.

E-mail address: berendien.lubbe@up.ac.za (B. Lubbe).
}

Murray suggested that literature could benefit from the application of gap-theory methodology for analysing service quality. As a result they developed, from best practices in marketing and services research, a conceptual theory-based model focussing on the dimensionality of passenger expectations of airport service quality. They conceded that in their study passenger data was collected in a "contextual void" because respondents were asked to indicate their expectation for airports in general, without taking into consideration passenger, trip or airport characteristics and they proposed that for the model to become a global measure it should also be tested in different locations. The research undertaken in South Africa serves to begin fulfilling this purpose.

Fodness and Murray argue that traditional airport market research has ignored the gap-theory method of service quality measurement where passenger expectations determine their level of satisfaction. They also argue that ignoring passenger expectations in service quality measurement could result in a misguided effort by airport management to improve services in ways that are unimportant to customers. To overcome this they developed a conceptual model for service quality expectations suggesting that passenger airport service quality expectations could be structured along three dimensions - function, interaction and diversion - with each dimension having sub-dimensions associated with them in the passengers' mind.

The function dimension has two sub-dimensions, the first relates to how effectively passengers move through an airport, basically how well people find their way to either their departure gate or facilities and amenities such as restrooms and restaurants; and the second to how efficiently passengers move through the airport; the timeliness of their movements. The second dimension, interaction, is mainly related to problem-solving behaviours of 


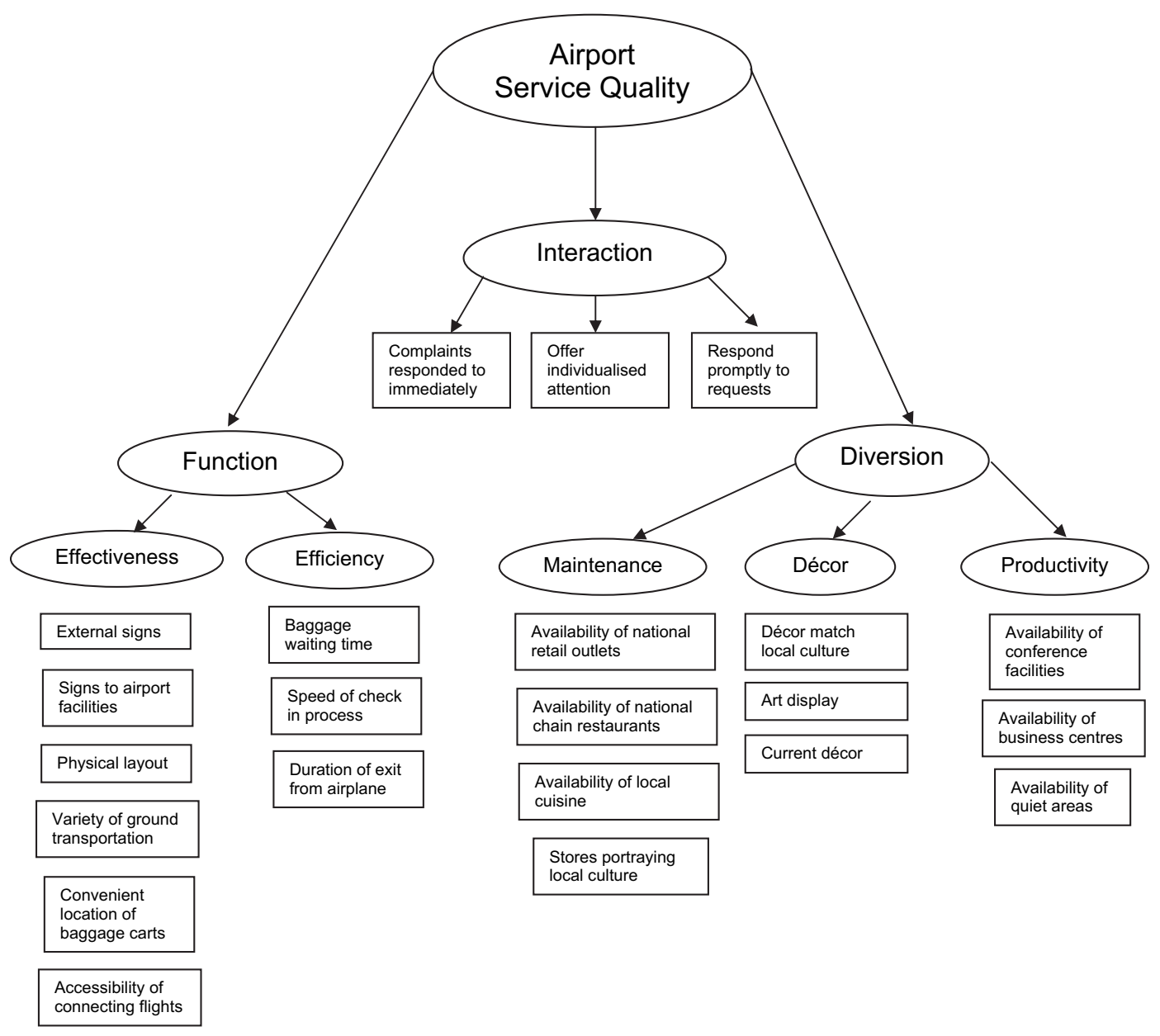

Fig. 1. Fodness and Murray's hierarchical structure for airport service quality expectations. Source: Fodness and Murray (2007: 502).

airport service personnel. Thus, where the customer's physical presence is required for service delivery, the interactions a passenger has with service providers influence the passenger's quality perceptions. Fodness and Murray describe the third dimension, diversion, as a "turning aside from focussing on the fact that the passenger is, in effect "trapped" in the airport servicescape toward activities that redirect their attention or stimulate them aesthetically." The sub-dimensions are referred to as productivity,

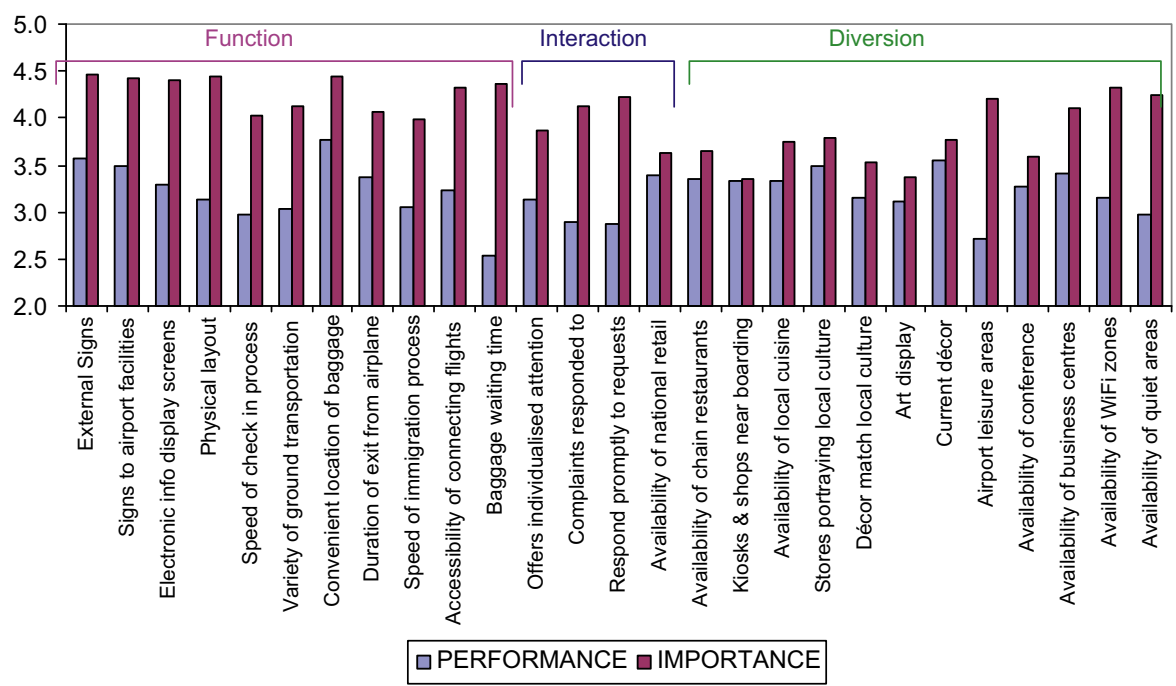

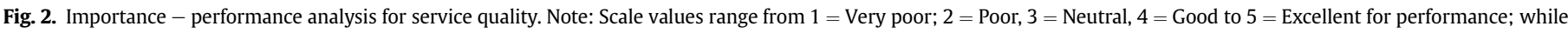
for importance they range from $1=$ Strongly disagree, $2=$ Disagree, $3=$ Neither agree or disagree, $4=$ Agree to $5=$ Strongly agree. 


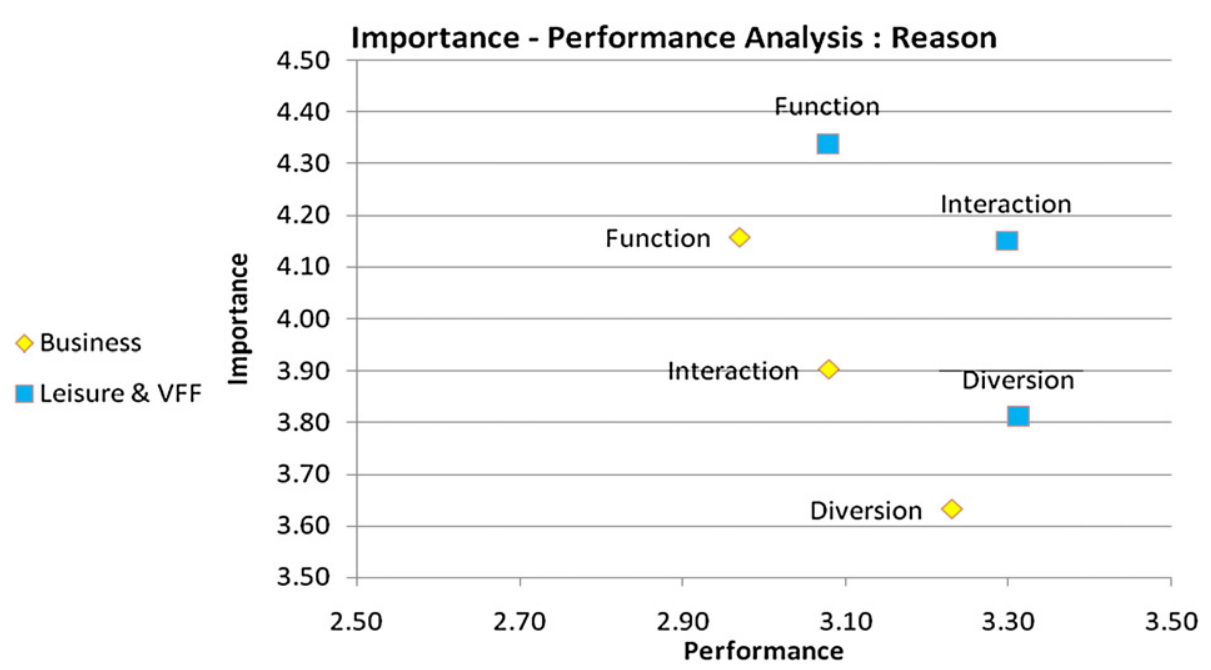

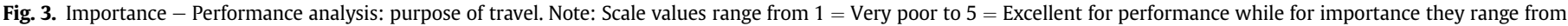
$1=$ Strongly disagree to $5=$ Strongly agree.

decor and maintenance, where the label 'diversion' captures in essence that the passenger is caught up in the airport experience.

Fodness and Murray's model, as depicted in Fig. 1, is used as the conceptual framework to evaluate whether ACSA was achieving its goal in meeting expectations regarding service quality at the OR Tambo International Airport in Johannesburg, and to look at the implications of its use in a different cultural context.

\section{Methodology}

The target population examined consists of passengers at the South African Airways (SAA) international departures check-in area of ORTIA. Data were collected using a convenience sampling method. This has obvious limitations but was used because of the strict security control regulations at the airport; for security reasons, SAA only provided permission for one researcher at their check-in counters. The questionnaires were distributed over five days, at different intervals during the day, to ensure that the sample was representative of all airline passengers. Because of the strict security 100 passengers completed the self administered survey. The questions asked reflect Fodness and Murray's multi dimensional scale to assess respondents' perceptions of the importance of airport service quality in general and performance relating to ORTIA specifically. Various questions were added and some rephrased to adjust to local conditions and airport characteristics. As a result the Cronbach Alpha values were calculated to ensure validity of the three dimensions - function, interaction and diversion - for both importance and performance, as well as for the subdimensions of each. Because the results are in the range of those of the original study, save for interaction, which is lower, they were not modified to allow comparison with the original study. Mean values were used as an indication of how respondents rate the importance and performance of specific items, and the dimensions and sub-dimensions of service quality in relation to ORTIA. ANOVA tests were conducted to explore whether there are significant differences in the service quality perceptions when travel is for different purposes, and at higher or lower frequencies.

\section{Results}

Sixty-nine percent of respondents are from South Africa and 27\% from Zimbabwe and the remaining $4 \%$ from other regions. Ninetytwo percent indicated that it was not their first visit to ORTIA, with
49\% having travelled through the airport one to three times in the last year. The main reason for trips was leisure and visiting friends and family (nearly 60\%) with over $90 \%$ of individuals flying economy class. Thirty-seven percent of respondents were between eighteen and thirty years old, with an equal distribution of married and single respondents, and of males and females.

Fig. 2 shows an analysis of the mean values of individual items in terms of their performance and importance rating by respondents. For the function dimension, clarity of external signs is perceived as the most important item, followed by convenience of baggage cart location. ORTIA's performance on these items is also highest but, while external signs achieved a slightly better result, both fell short of being in the "good" range. For the diversion dimension, passengers rated WiFi areas as the most important item followed by leisure areas where passengers can sit comfortably watching TV and listening to music. Performance levels on these items are scored lower than expected when compared to the level of importance of the items assigned by travellers. The least important aspect to passengers is the availability of portable kiosks and shops near the boarding gates, as well as the display of art in the terminal. Regarding interactions, prompt response to requests and immediate response to complaints rate the highest in terms of importance; but on the performance scale both items are rated in the poor to neutral range.

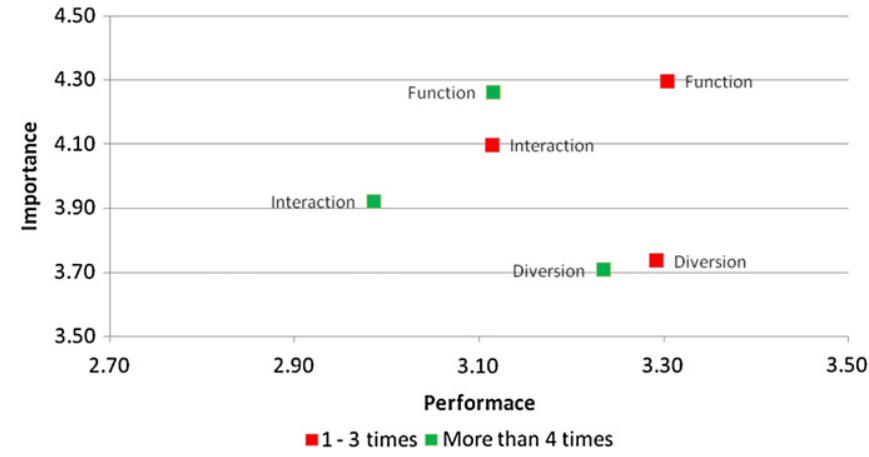

Fig. 4. Importance - Performance analysis: frequency of travel. Note: Scale values range from $1=$ Very poor to $5=$ Excellent for performance while for importance they range from $1=$ Strongly disagree to $5=$ Strongly agree. 
Table 1

One-way ANOVA: importance and performance: frequency of travel.

\begin{tabular}{lll}
\hline & & $P$ Value \\
\hline Importance Interaction & Between Groups & $0.036^{\mathrm{a}}$ \\
& Within Groups & 0.356 \\
\hline
\end{tabular}

a Indicates a significant difference between groups on a 5\% level of significance.

Table 2

One-way ANOVA: Importance and performance: purpose of travel.

\begin{tabular}{lll}
\hline & & $P$ Value \\
\hline Importance Function & Between Groups & $0.063^{\mathrm{a}}$ \\
& Within Groups & 0.196 \\
Importance Interaction & Between Groups & \\
& Within Groups & $0.062^{\mathrm{a}}$ \\
Importance Diversion & Between Groups & 0.364 \\
& Within Groups & $0.090^{\mathrm{a}}$ \\
Performance Function & Between Groups & 0.233 \\
& Within Groups & $0.062^{\mathrm{a}}$ \\
\hline a & & 0.285 \\
\hline
\end{tabular}

${ }^{a}$ Indicates a significant difference between groups on a $10 \%$ level of significance.

Regarding the overall dimensions, it is found that on average for all respondents interaction rated as the most important feature of airport service quality while function was second, followed by diversion. ORTIA's overall performance in these areas is rated as follows: the diversion features (productivity, décor and maintenance) are rated the highest, followed by function (effectiveness and efficiency) and lastly interaction features. While airport personnel and passenger interaction is rated as the most important by passengers, its performance rating is the weakest.

Fig. 3 reports the importance and performance findings with respect to purpose of travel. Functionality is the most important to both leisure and business travellers although for both groups this dimension has the lowest value in terms of performance at ORTIA. Diversion is rated the best in performance at ORTIA for leisure travellers while for business travellers it is rated quite low. The interaction dimension is more important for leisure travellers than for business travellers, and similarly, performance in the interaction dimension at ORTIA is rated higher by leisure travellers than by business travellers.

Fig. 4 shows the results of the importance-performance analysis according to frequency of travel through ORTIA based on the mean values. Frequent travellers are defined as those who had travelled via ORTIA more than three times in the previous year. Those passengers who had only travelled three times or less rate the function dimension as most important followed by interaction, while both function and diversion are rated approximately the same in terms of performance. However, frequent travellers rate ORTIA's performance considerably lower in these dimensions.

To see if there are significant differences between groups in terms of their perceptions of the importance and performance of the three service quality dimensions, one-way ANOVA tests were performed. The results are shown in Tables 1 and 2. Table 1 indicates that the importance of the dimension interaction to frequent and infrequent travellers differ significantly at the 5\% level.

Table 2 indicates that business and leisure travellers may differ in terms of the importance attributed to all three dimensions. In evaluating performance, a trend emerges that business and leisure travellers may differ on the function dimension.

\section{Conclusions}

On a global scale, the importance of service quality measurement and management at airports is seen as important but for airport service strategies to yield the desired results, passengers themselves need to be the ones to define and evaluate service. The study investigated passengers' perceptions of the importance of airport service quality dimensions, according to the model found in Fodness and Murray (2007), and assessed the performance of ORTIA along these dimensions in a South African context. When function, interaction and diversion are compared, passengers describe interaction as the most important, followed by function and diversion signifying that it is the service one receives from airport personnel that may ultimately determine whether an experience at ORTIA was satisfactory. Overall ORTIA's performance however, is best in the diversion dimension, followed by function and lastly by interaction; the reverse ordering.

Fodness and Murray also felt that there is a need to take purposes and frequencies of travel into account, as well as an airport's characteristics. Our results provide some evidence that purpose and frequency can influence the importance passengers place on particular service quality attributes, as well as their ratings of the specific airport they are departing from. Business passengers find interaction, function and diversion less important than do leisure travellers, and also rate ORTIA's performance in these dimensions weaker than leisure passengers. Further, the more often a passenger travels the lower they rate ORTIA's overall performance although the importance they placed on the service dimensions are relatively the same.

\section{References}

Airports Company South Africa, 2010. Airports readying for the world cup. Available from. <http://www.acsa.co.za/home.asp?pid=94\&toolid=2\&itemid=6530 > (accessed: 23.04.10.).

Fodness, D., Murray, B., 2007. Passengers' expectations of airport service quality. Journal of Services Marketing 21, 492-506. 